\title{
A BANALIZAÇÃO DOS PRINCÍPIOS DA RAZOABILIDADE E DA PROPORCIONALIDADE NO CONTROLE DIFUSO DE CONSTITUCIONALIDADE E SEPARAÇÃO DE PODERES ${ }^{1}$
}

THE BANALIZATION OF THE PRINCIPLES OF REASONABILITY AND PROPORTIONALITY IN DIFFUSION CONTROL OF CONSTITUTIONALITY AND SEPARATION OF POWERS

Danilo Henrique Nunes Advogado e professor universitário. Mestre em Direitos Coletivos e Cidadania - programa com conceito 4 no Capes/MEC. Barretos/SP. E-mail: dhnunes@ hotmail.com

Sebastião Sérgio Silveira Professor pós-doutor em Direito pela Universidade de Coimbra, Portugal e doutor pela PUC/SP. Coordenador do programa de Mestrado em Direitos Coletivos e Cidadania programa com conceito 4 no Capes/MEC. Ribeirão Preto/SP. E-mail: ssilveira@unaerp.br

Fernanda Morato Silva Mestranda em Direitos Coletivos e Cidadania. Advogada e professora universitária. Universidade de Ribeirão Preto Unaerp - Ribeirão Preto/SP. Ribeirão Preto/SP. E-mail: fernandamorato@live.com

RESUMO: Em âmbito nacional, a utilização dos princípios e regras correlacionadas à proporcionalidade e à razoabilidade vêm levantando uma série de controvérsias e embates jurídicos. É observada na jurisprudência brasileira uma ampla banalização dos mesmos, que são recorridos de modo demasiado e na maior parte dos casos sendo aplicados como

\footnotetext{
${ }^{1}$ Artigo recebido em 23/10/2018 e aprovado em 29/07/2019.
} 
Revista Eletrônica de Direito Processual - REDP.

Rio de Janeiro. Ano 13. Volume 20. Número 2. Maio a Agosto de 2019

Periódico Quadrimestral da Pós-Graduação Stricto Sensu em Direito Processual da UERJ

Patrono: José Carlos Barbosa Moreira (in mem.). ISSN 1982-7636. pp. 74-95

www.redp.uerj.br

sinônimos, o que não é permitido pela estrutura, metodologia e origem tanto da proporcionalidade quanto da razoabilidade. O presente estudo busca aprofundar as consequências de tal banalização no âmbito da aplicação de tais princípios no contexto jurídico atual, sobretudo no âmbito do controle difuso de constitucionalidade e no respeito ao princípio da separação de poderes, elementos que assim como os princípios da proporcionalidade e razoabilidade, sustentam e orientam o funcionamento do Estado Democrático de Direito a partir do pleno respeito e observância às normas e princípios constitucionais. $\mathrm{O}$ estudo em questão parte de premissas envolvendo os princípios jurídicos em caráter geral, bem como os princípios de estudo específico e o controle difuso de constitucionalidade e a separação de poderes, passando de questões gerais para a questão específica, aprofundando como a banalização de tais princípios promove impactos na desobediência ao princípio constitucional da separação de poderes e consequentemente no controle difuso de constitucionalidade.

PALAVRAS-CHAVE: Proporcionalidade e Razoabilidade; Separação de Poderes; Controle Difuso de Constitucionalidade.

ABSTRACT: At national level, the use of principles and rules correlated with proportionality and reasonableness has been raising a series of controversies and legal conflicts. It is observed in the Brazilian jurisprudence a wide banalization of the same ones, that are traveled of way too and in the majority of the cases being applied like synonyms, which is not allowed by the structure, methodology and origin of both proportionality and reasonableness. The present study seeks to deepen the consequences of such banalization in the scope of application of such principles in the current legal context, especially in the scope of diffuse control of constitutionality and respect for the principle of separation of powers, elements that as well as the principles of proportionality and reasonableness, sustain and guide the functioning of the Democratic Rule of Law, based on full respect for and observance of constitutional norms and principles. The study in question starts from premises involving general legal principles, as well as the principles of specific study and the diffuse control of constitutionality and the separation of powers, going from general questions to the specific question, deepening as the trivialization of 
Revista Eletrônica de Direito Processual - REDP.

Rio de Janeiro. Ano 13. Volume 20. Número 2. Maio a Agosto de 2019

Periódico Quadrimestral da Pós-Graduação Stricto Sensu em Direito Processual da UERJ

Patrono: José Carlos Barbosa Moreira (in mem.). ISSN 1982-7636. pp. 74-95

www.redp.uerj.br

such principles promotes impacts in disobedience to the constitutional principle of the separation of powers and consequently in the diffuse control of constitutionality.

KEYWORDS: Proportionality and Reasonability; Separation of Powers; Diffuse Control of Constitutionality.

\section{INTRODUÇÃO}

Em meio a uma série de debates acerca das concepções jurídicas que permeiam na realidade brasileira atual, sobretudo envolvendo o respeito ao Diploma Constitucional de 1988 e ao funcionamento do Estado Democrático de Direito encontram-se as mais diversas questões contempladas na perspectiva da aplicabilidade dos princípios da razoabilidade e da proporcionalidade, os quais equivocadamente são abordados pelo Judiciário como sinônimos, além de invocados de maneira recorrente e demasiada, o que acaba por proporcionar a banalização de tais princípios, culminando em consequências jurídicas que clamam por uma maior atenção dos doutrinadores e dos juristas em caráter geral.

O presente estudo busca analisar a banalização dos princípios da razoabilidade e da proporcionalidade dentro do contexto jurídico contemporâneo, sobretudo levando em consideração que a banalização e confusão entre ambas as concepções jurídicas detém caráter histórico, diante da assimilação de ambos para a formulação, desenvolvimento e manutenção do Estado Democrático de Direito.

Analisar a banalização de tais princípios, entretanto, só é uma atividade jurídica válida quando são analisadas as consequências da invocação e utilização trivial dos mesmos. A demonstração de tais consequências no presente estudo, de tal forma, dará ênfase para a banalização da proporcionalidade e razoabilidade no controle difuso de constitucionalidade, bem como na obediência ao princípio de separação dos poderes, elementos os quais funcionam como um sustentáculo para que o Estado Democrático de Direito opere dentro dos limites estabelecidos pelo constituinte.

O estudo em questão parte das concepções fundamentais dos princípios jurídicos e do Estado Democrático de Direito, apresentando as concepções fundamentais envolvidas 
Revista Eletrônica de Direito Processual - REDP.

Rio de Janeiro. Ano 13. Volume 20. Número 2. Maio a Agosto de 2019

Periódico Quadrimestral da Pós-Graduação Stricto Sensu em Direito Processual da UERJ

Patrono: José Carlos Barbosa Moreira (in mem.). ISSN 1982-7636. pp. 74-95

www.redp.uerj.br

no tema, propiciando ainda explicações conceituais acerca da razoabilidade e da proporcionalidade, buscando distinguir ambos os princípios, bem como a realização da apresentação de elementos fundamentais para o pleno entendimento do controle difuso de constitucionalidade e da separação de poderes. Através de tais elucidações, torna-se possível observar e analisar a banalização de tais princípios, bem como suas consequências nesses dois eixos norteadores do Estado Democrático de Direito e das prerrogativas constitucionais.

\section{OS PRINCÍPIOS JURÍDICOS E O ESTADO DEMOCRÁTICO DE DIREITO}

De acordo com Celso Antônio Bandeira de $\mathrm{Mello}^{2}$ os princípios funcionam dentro do ordenamento jurídico como mandamentos que devem ser seguidos de modo lógico para incorporar a racionalidade do sistema normativo, dando sentido harmônico para as leis. Para o autor, os princípios são ideias centrais dentro do sistema jurídico, com o intuito de proporcionar maior lógica e racionalidade quanto ao seu modo de organização, sendo considerados superiores hierarquicamente às regras, determinando seu sentido e alcance, de modo que as regras não podem contrariá-los.

Virgílio Afonso da Silva ${ }^{3}$ leciona que que os princípios jurídicos podem ser identificados de modo implícito ou explícito dentro de um determinado ordenamento jurídico, constituindo-se como normas jurídicas. Os princípios, entretanto, devem ser inquestionáveis, uma vez que os mesmos estão vinculados aos valores primordiais da sociedade para que se produza a justiça. Para que se produza justiça com base no ordenamento jurídico, de tal modo, é indispensável que sejam observados e seguidos os princípios determinantes do ordenamento em si.

Ivo Dantas ${ }^{4}$, por sua vez, contempla que os princípios jurídicos devem ser aplicados tanto na elaboração das leis quanto na plena aplicação do direito, contribuindo para nortear as interpretações jurídicas preenchendo as lacunas existentes dentro das legislações. $\mathrm{O}$ autor realiza em sua obra uma distinção entre as regras e princípios, contemplando os

\footnotetext{
${ }^{2}$ MELLO, Celso Antônio Bandeira de apud SUNDELD, Carlos Ari Sundeld. Fundamentos de direito público. 3. ed. São Paulo: Ed. Malheiros, 2009.

${ }^{3}$ SILVA, Virgílio Afonso da. Princípios e regras: mitos e equívocos acerca de uma distinção. In: Revista Latino-Americana de Estudos Constitucionais n. 1, 2003, p. 607-630.

${ }^{4}$ DANTAS, Ivo. Princípios constitucionais e interpretação constitucional. Rio de Janeiro: Lumen Juris, 1995.
} 
Revista Eletrônica de Direito Processual - REDP.

Rio de Janeiro. Ano 13. Volume 20. Número 2. Maio a Agosto de 2019

Periódico Quadrimestral da Pós-Graduação Stricto Sensu em Direito Processual da UERJ

Patrono: José Carlos Barbosa Moreira (in mem.). ISSN 1982-7636. pp. 74-95

www.redp.uerj.br

princípios como normas jurídicas lógicas as quais são prévias e superiores

hierarquicamente às regras, servindo de fundamento básico para sua criação, aplicação e interpretação; as regras, em contrapartida, são normas jurídicas fundamentadas para que os princípios jurídicos sejam concretizados.

Nesse sentido, Lênio Luiz Streck:

\begin{abstract}
Princípios funcionam, assim, como Leitmotiv do processo interpretativo, como que a mostrar que cada enunciado jurídico possui uma motivação. Princípios têm a função de mostrar/denunciar a ruptura com a plenipotenciaridade das regras; o direito não isenta o intérprete de qualquer compromisso com a realidade. As decisões sempre devem ser feitas a partir de princípios e não de políticas (ou critérios de razão prática). É isso que se quer dizer quando falamos de "princípios". 5
\end{abstract}

De acordo com Eduardo de Azevedo Paiva $^{6}$ os princípios jurídicos podem ser contemplados sob diferentes características, a exemplo da existência dos princípios gerais norteadores do Direito e dos princípios constitucionais. $\mathrm{O}$ autor apresenta tal distinção contemplando que os princípios gerais de direito servem como última alternativa ao preenchimento das lacunas contidas na lei, enquanto os princípios constitucionais se prestam ao preenchimento de omissões do legislador através de sua derradeira fórmula.

Pessoa $^{7}$ aponta que sempre que a lei se revelar omissa, o magistrado embasa sua decisão de acordo com a analogia, os costumes e os princípios gerais do direito. Entretanto, a autora aponta duas diferentes caracterizações acerca dos princípios gerais do direito: enquanto uma corrente defende que tais princípios seriam chamados de direito natural, outra corrente defende que os princípios gerais do direito contemplam regras gerais baseadas na equidade e induzidas pela Ciência e pela Filosofia do Direito nos sistemas jurídicos, com base na universalidade.

Nesse sentido, ainda segundo a autora supramencionada, tais princípios sempre serviram de base para a elaboração de regras positivas, tendo caráter incontestável de fonte

\footnotetext{
${ }^{5}$ STRECK, Lenio Luiz. As Recepções Teóricas Inadequadas Em Terrae Brasilis. In: Revista de Direitos Fundamentais e Democracia, Curitiba, v. 10, n. 10, p. 2-37, jul. / dez. 2011, p. 27.

6 PAIVA, Eduardo de Azevedo. Princípios Gerais de Direito e Princípios Constitucionais. Série Aperfeiçoamento de Magistrados 11 - Curso de Constitucional - Normatividade Jurídica, 2012.

7 PESSOA, Laura Scalldaferri. Os Princípios Gerais do Direito na Integração das Normas. In: Revista REDE, n. 20, Salvador, out-dez/2009.
} 
supletiva no que diz respeito às lacunas jurídicas, dado que o próprio ordenamento jurídico lhe assegura tal posição. A concepção positiva é a mais adequada acerca dos princípios gerais de direito, de modo que os mesmos podem ser contemplados como princípios racionais superiores de ética social e também princípios de direito romano e universalmente admitidos na doutrina jurídica, tendo sua base na informação efetiva do sistema positivo do direito, estabelecendo-se enquanto princípios de Direito positivo e vigente.

Já os princípios constitucionais, conforme leciona José Afonso da Silva ${ }^{8}$, são aqueles que condensam os valores e bens considerados de validade em todo o sistema jurídico, uma vez que o Diploma Constitucional é contemplado como a Lei Maior de um sistema jurídico. Esses princípios são referentes à conduta individual de todos os indivíduos sujeitos ao ordenamento jurídico e também do Estado Democrático de Direito.

A partir de tais fundamentos, é sempre importante observar e obedecer aos princípios maiores diante dos menores ou subentendidos, visto que os princípios jurídicos, expressos ou não, são representativos quanto aos direitos e garantias dos administrados diante do Poder Estatal. Os princípios coíbem que sejam praticados abusos, salvaguardando a integridade dos indivíduos, do Estado Democrático de Direito e do próprio sistema jurídico, sendo um denominador constante para a elaboração e interpretação das normas jurídicas.

\section{OS PRINCÍPIOS DA RAZOABILIDADE E DA PROPORCIONALIDADE}

De acordo com Helenilson Cunha Pontes ${ }^{9}$ o princípio da proporcionalidade tem fulcro justamente na evolução dos direitos e garantias individuais inerentes a pessoa humana, a partir do surgimento do Estado de Direito na Europa. Para o autor, a origem do princípio da personalidade advém das teorias jus naturalistas inglesas que propunham que o homem deveria ter direitos relacionados à sua natureza, devendo o Estado na medida de sua Soberania ter a obrigação de respeitá-los.

\footnotetext{
${ }^{8}$ SILVA, José Afonso da. Os princípios constitucionais fundamentais. In: Revista do Tribunal Regional Federal, 1. edição, Brasília, out/dez, 1994, p. 17-22.

9 PONTES, Helenilson Cunha. O princípio da proporcionalidade e o direito tributário. São Paulo: Dialética, 2000.
} 
Revista Eletrônica de Direito Processual - REDP.

Rio de Janeiro. Ano 13. Volume 20. Número 2. Maio a Agosto de 2019

Periódico Quadrimestral da Pós-Graduação Stricto Sensu em Direito Processual da UERJ

Patrono: José Carlos Barbosa Moreira (in mem.). ISSN 1982-7636. pp. 74-95

www.redp.uerj.br

A concepção fundamental por trás do princípio da proporcionalidade, de acordo com o autor supramencionado, diz respeito ao ideal de que o homem deve ser punido na devida proporção ao delito por ele cometido, ou seja, de acordo com a gravidade de tal delito e não por maior ou menor proporção.

Ana Paula Caldin da Silva ${ }^{10}$ aponta que o princípio da proporcionalidade detém como função principal a solução de colisões entre os direitos fundamentais quando diante de um ato estatal destinado à promoção da realização de um direito fundamental, de modo que a proporcionalidade deve ser empregada como regra de interpretação e aplicação do direito. A autora aponta que a aplicação de tal princípio diante da colisão entre direitos fundamentais ou princípios, entretanto, não implica diretamente na exclusão de um dos direitos conflitantes.

De acordo com Karina Roberto e Nelson Finotti Silva ${ }^{11}$ a importância da proporcionalidade no âmbito jurídico diz respeito justamente à vocação do princípio que busca compatibilizar a consideração das realidades não captadas ou marginalizadas pelo formalismo jurídico, levando o que há de mais novo no constitucionalismo contemporâneo projetado sobre a vida concreta. Os autores apontam que o princípio existe para evitar o excesso de obediência a um princípio que destrói o outro, assim aniquilando os dois, de modo que o princípio da proporcionalidade se dá em conta da necessidade, intrínseca ao funcionamento do Estado Democrático de direito, no âmbito de seu reconhecimento e emprego dentro do contexto jurídico.

Conforme apontado por Virgínia de Oliveira Rosa Dobrianskyj ${ }^{12}$ o princípio da proporcionalidade é um dos mais importantes do âmbito jurídico e talvez o mais importante sob a ótica do direito penal, pois busca assegurar que não seja eliminado um direito fundamental quando em conflito com outro, respeitando seu núcleo essencial. Para a autora, trata-se de um princípio construtivo, fundamental, implícito e pressuposto entre o Estado de Direito e a Democracia, tendo a função de hierarquizar, nas situações de

\footnotetext{
${ }^{10}$ SILVA, Ana Paula Caldin da. Aplicação dos princípios da razoabilidade e da proporcionalidade na jurisprudência tributária brasileira. Dissertação (Mestrado em Direito Político e Econômico) Universidade Presbiteriana Mackenzie, São Paulo, 2010.

${ }^{11}$ ROBERTO, Karina; SILVA, Nelson Finotti. A regra da proporcionalidade e o princípio da razoabilidade. In: Revista Eletrônica Direito e Política, Programa de Pós-Graduação Stricto Sensu em Ciência Jurídica da UNIVALI, Itajaí, v.7, n.2, 2º quadrimestre de 2012.

12 DOBRIANSKYJ, Virgínia de Oliveira Rosa. O princípio da proporcionalidade como critério de aplicação da pena. Dissertação apresentada à Pontifícia Universidade Católica (PUC) de São Paulo. São Paulo, 2009.
} 
Revista Eletrônica de Direito Processual - REDP.

Rio de Janeiro. Ano 13. Volume 20. Número 2. Maio a Agosto de 2019

Periódico Quadrimestral da Pós-Graduação Stricto Sensu em Direito Processual da UERJ

Patrono: José Carlos Barbosa Moreira (in mem.). ISSN 1982-7636. pp. 74-95

www.redp.uerj.br

conflitos, os demais princípios, buscando a concretização dos direitos, tendo sua relevância associada à ordenação da aplicação dos princípios constitucionais, possibilitando que haja o maior atendimento a estes, com mínima desatenção aos demais.

Ronald Dworkin ${ }^{13}$ aponta, dentro desse contexto, que os princípios devem seguir um padrão normativo para compor um ordenamento jurídico ao lado das regras. Tal reconhecimento da força normativa dos princípios possibilita que o julgador possa decidir eventuais questões fundamentando sua decisão em princípios integrados ao ordenamento, propiciando o processo decisório de maneira inteiramente jurídica. Para o autor, os princípios sempre estarão em traçado de colisão, uns com os outros, de modo a restringirem-se reciprocamente, não se podendo dizer que um deles será aplicado ao caso concreto e outro não.

Josué Mastrodi ${ }^{14}$ ao analisar a teoria dos direitos fundamentais de Robert Alexy, apontou que a proporcionalidade é ampliada servindo como base para comparação e aplicação ponderada de direitos e interesses que entram em rota de conflito, uma vez que a proporcionalidade da teoria dos direitos fundamentais relaciona a decisão tomada com o critério utilizado pelo julgador a decidir, objetivando a ponderação entre direitos em colisão.

(...) dado o sucesso da teoria de Alexy, toda ponderação acaba por fazer referência à proporcionalidade de sua teoria dos direitos fundamentais, com seus subtestes de adequação, necessidade e proporcionalidade em sentido estrito. A proporcionalidade da teoria de Alexy acaba se apresentando como o modelo a ser seguido em todas as práticas de resolução de conflitos entre direitos fundamentais. Todo modelo, toda representação de um objeto por algo diferente desse mesmo objeto é, por definição, fictício. ${ }^{15}$

Conforme ensinamento de Virgílio Afonso da Silva ${ }^{16}$ há um problema terminológico na classificação do mesmo enquanto princípio, sobretudo com base na classificação de Alexy, uma vez que não produz efeito em várias medidas, já que é

\footnotetext{
${ }^{13}$ DWORKIN, Ronald. Uma questão de princípio. Trad. Luis Carlos Borges. 2a ed. São Paulo: Martins Fontes, 2005.

${ }^{14}$ MASTRODI, Josué. Ponderação De Direitos E Proporcionalidade Das Decisões Judiciais. In: Revista Direito FGV, São Paulo, 2014, p. 577-596.

${ }^{15}$ MASTRODI, Josué. Op. Cit., p. 584.

${ }^{16}$ SILVA, Virgílio Afonso da. O proporcional e o razoável. Revista dos Tribunais 798 (2002): 23-50.
} 
Revista Eletrônica de Direito Processual - REDP.

Rio de Janeiro. Ano 13. Volume 20. Número 2. Maio a Agosto de 2019

Periódico Quadrimestral da Pós-Graduação Stricto Sensu em Direito Processual da UERJ

Patrono: José Carlos Barbosa Moreira (in mem.). ISSN 1982-7636. pp. 74-95

www.redp.uerj.br

aplicado constantemente, sem variações, de modo que o autor o enquadra como uma regra, visto que o doutrinador entende que somente regras asam aplicadas por meio de subsunção.

Para Andreia Narrimán Cezne ${ }^{17}$ a teoria dos princípios de Dworkin é o ponto principal que aproxima o pensamento de Alexy ao do doutrinador, de modo que a enunciação de regras e princípios realizadas pelo primeiro é aceita pelo segundo, que busca sofisticá-la. Para Dworkin, o sistema de princípios possibilita que exista uma resposta concreta nos casos nos quais as regras não determinam uma única resposta. Assim, a única resposta correta seria aquela que melhor se justificar dentro de uma teoria substantiva, que tenha como elementos os princípios e ponderações de princípios que melhor correspondem ao entendimento constitucional, às regras norteadoras do direito e aos precedentes jurídicos.

A partir de tal concepção baseada nas teorias de Dworkin e Alexy, torna-se possível aprofundar também a razoabilidade. Virgílio Afonso da Silva ${ }^{18}$ aponta que no discurso jurídico, quando se fala em princípio da razoabilidade ou em princípio ou regra da proporcionalidade, ambos não devem ser concebidos como sinônimos, pois expressam construções jurídicas diversas, ainda que detenham objetivos jurídicos semelhantes. Tal distinção se faz observada não tão somente nas suas origens, mas também em suas estruturas.

$\mathrm{O}$ autor, em seu estudo, fundamenta tal concepção seguindo algumas teses, são elas:

A aplicação da regra da proporcionalidade pelo Supremo Tribunal Federal, com base na jurisprudência, consiste tão somente em um apelo à razoabilidade;

As 'sub-regras' da proporcionalidade guardam relação de subsidiariedade, de modo que nem sempre será necessária a aplicação de todas as 'subregras';

A regra da proporcionalidade decorre logicamente do fato de os direitos fundamentais serem considerados princípios e não regras, de modo que não há previsão constitucional a respeito;

\footnotetext{
${ }^{17}$ CEZNE, Andreia Nárriman. A teoria dos direitos fundamentais: uma análise comparativa das perspectivas de Ronald Dworkin e Robert Alexy. In: Revista de Direito Constitucional e Internacional, v.13, n. 52, São Paulo: 2005, p. 51- 67.

${ }^{18}$ SILVA, Virgílio Afonso da. Op. Cit.
} 
Revista Eletrônica de Direito Processual - REDP.

Rio de Janeiro. Ano 13. Volume 20. Número 2. Maio a Agosto de 2019

Periódico Quadrimestral da Pós-Graduação Stricto Sensu em Direito Processual da UERJ

Patrono: José Carlos Barbosa Moreira (in mem.). ISSN 1982-7636. pp. 74-95 www.redp.uerj.br

Ainda que o STF sustente a fundamental importância da regra da proporcionalidade no âmbito da colisão de direitos fundamentais, aplica-se o princípio da razoabilidade com o intuito de ir além, objetivando a aplicação sistemática de um modelo já existente, fomentando a coerência no processo decisório.

Assim:

Note-se que a regra da proporcionalidade se difere do princípio da razoabilidade, pois este será utilizado sempre que for necessária a verificação de compatibilidade entre o meio escolhido e o fim visado pelo poder público para constatação de abuso de poder ou limitação desnecessária aos direitos e garantias individuais, conceito que será melhor estudado em capítulo próprio. É do modo de solução do conflito entre princípios que se induz a regra da proporcionalidade, sendo necessário averiguar qual dos princípios colidentes terá maior peso e que deverá prevalecer no caso concreto. ${ }^{19}$

A partir de tal elucidação, Leonardo Carneiro Vilhena ${ }^{20}$ aponta que a proporcionalidade e a razoabilidade são consideradas regras (ou princípios) que viabilizam a observância do devido processo legal substantivo, permitindo o funcionamento do Estado Democrático de Direito e preservando os Direitos e Garantias Fundamentais. Por serem princípios inerentes emanados do próprio sistema normativo democrático, os mesmos podem ou não estarem expressamente transcritos, mas devem ser aplicados em todas as formas de expressão da norma jurídica, a exemplo do que faz o STF, que considera presentes tais princípios, mesmo que os mesmos não estejam expressos de modo tácito no Diploma Constitucional de 1988.

Nesse sentido:

De fato, é de se perceber que o princípio da proporcionalidade possui uma substância mais profunda, emanada do próprio Estado Democrático de Direito, que preza pela ideia da prevalência de direitos e garantias fundamentais dos administrados e o afastamento de disposições arbitrárias e unilaterais que

\footnotetext{
${ }^{19}$ ROBERTO, Karina; SILVA, Nelson Finotti. Op. Cit., p. 1570.

20 VILHENA, Leonardo Carneiro. Os Princípios Constitucionais Da Razoabilidade E Da Proporcionalidade E O Direito Tributário. Monografia apresentada ao Pós-Graduação Lato Sensu do Instituto Brasiliense de Direito Público - IDP, Brasília, 2011, p. 20.
} 
Revista Eletrônica de Direito Processual - REDP.

Rio de Janeiro. Ano 13. Volume 20. Número 2. Maio a Agosto de 2019

Periódico Quadrimestral da Pós-Graduação Stricto Sensu em Direito Processual da UERJ

Patrono: José Carlos Barbosa Moreira (in mem.). ISSN 1982-7636. pp. 74-95

www.redp.uerj.br

caracterizam um Estado Absoluto. Por outro lado, a razoabilidade vai além dos

meros requisitos formais, sendo justificada sua aplicação sempre que os requisitos formais (racionais) forem insuficientes. Este princípio busca o máximo de consenso (e de bom senso) nas decisões, através de um sopesamento de princípios que devem se ajustar a cada caso concreto. ${ }^{21}$

Alexandre Sivolella Peixoto ${ }^{22}$ conceitua o princípio da razoabilidade como um método utilizado no Direito para sanar conflitos entre princípios jurídicos, baseado na aplicação do bom-senso no âmbito jurídico, que se faz necessário para que sejam cumpridas as exigências formais emanadas do princípio da legalidade, que reforça mais o texto das normas do que o espírito das leis.

Fábio de Oliveira ${ }^{23}$, no mesmo sentido contempla que a razoabilidade estabelece os critérios formais e os critérios materiais para que sejam ponderados princípios e regras, sendo um parâmetro para a valoração dos atos do Estado para que se produza a justiça. No ordenamento jurídico pátrio, o princípio da razoabilidade pode ser observado, a título de exemplo, no artigo $5^{\circ}$, inciso LXXVIII do Diploma Constitucional vigente, que assegura a todos no âmbito judicial e administrativo, a razoável duração do processo e os meios que garantam a celeridade de sua tramitação.

\section{CONTROLE DIFUSO DE CONSTITUCIONALIDADE}

Luís Roberto Barroso ${ }^{24}$ aponta que o controle difuso de constitucionalidade surgiu nos Estados Unidos em 1803, no julgamento do caso William Marbury versus James Madison, caso no qual o julgador John Marshall afirmou a supremacia das normas constitucionais no ordenamento jurídico norte-americanos, fixando que os atos normativos não podem ser editados em desconformidade com aquilo que é disposto pelo constituinte, de modo que coube ao Poder judiciário decidir em que momento e em que medida um determinado ato violou a Constituição do país. O controle difuso de constitucionalidade,

\footnotetext{
${ }^{21}$ VILHENA, Leonardo Carneiro. Op. cit., p. 20.

${ }^{22}$ PEIXOTO, Alexandre Sivolella et al. O princípio da razoabilidade. In: Revista Jurídica UNIGRAN. v. 6 , n. 11, Dourados, MS: 2004.

${ }^{23}$ OLIVEIRA, Fábio de. Por uma teoria dos princípios - o princípio constitucional da razoabilidade. 2 ed. Rio de Janeiro: Lúmen Juris, 2007.

${ }^{24}$ BARROSO, Luís Roberto. Controle de Constitucionalidade no Direito Brasileiro. 2. Ed. Rio de Janeiro: Saraiva, 2006.
} 
Revista Eletrônica de Direito Processual - REDP.

Rio de Janeiro. Ano 13. Volume 20. Número 2. Maio a Agosto de 2019

Periódico Quadrimestral da Pós-Graduação Stricto Sensu em Direito Processual da UERJ

Patrono: José Carlos Barbosa Moreira (in mem.). ISSN 1982-7636. pp. 74-95

www.redp.uerj.br

assim, embasa o exercício da jurisdição por membros do Poder Judiciário (juízes e órgãos colegiados), de modo que o magistrado ou o tribunal verificam as normas aplicáveis em caso concreto para sua apreciação com a legislação constitucional, deixando de aplicar quaisquer normas contrárias ao Diploma Constitucional.

Para Bruna Fernandes Coêlho ${ }^{25}$ o sistema difuso possibilita que qualquer juiz ou tribunal (na medida das regras de competência) realizem o controle de constitucionalidade, de modo que o controle difuso é verificado em cada caso concreto, com a declaração de inconstitucionalidade que se dá de modo incidental (incidenter tantum) prejudicialmente ao exame de mérito. A inconstitucionalidade de uma lei, assim, é a causa de requisição do processo, cabendo ao juiz examinar o mérito da ação. Nesse sentido:

O pedido principal não é a declaração de inconstitucionalidade, mas tal declaração enseja o acatamento do pedido. Em sede recursal, a denominada cláusula de reserva de plenário determina que "somente pelo voto da maioria absoluta de seus membros ou dos membros do respectivo órgão especial poderão os tribunais declarar a inconstitucionalidade de lei ou ato normativo do Poder Público". A declaração de inconstitucionalidade através do controle difuso gera efeitos retroativos, tornando a lei nula desde sua edição. Seguindo a regra geral dos efeitos de uma sentença, tal declaração de inconstitucionalidade gera efeitos entre as partes do processo. Entretanto, atualmente há a prevalência da "transcendência dos motivos determinantes da sentença em controle difuso". ${ }^{26}$

Vânia Hack Almeida ${ }^{27}$ aponta que o controle de constitucionalidade é difuso quando o mesmo pode ser realizado por todo e qualquer juiz, com base na Constituição e não na lei, sempre que houver incompatibilidade entre elas, aplicando sempre a Constituição e não a lei sob a qual é deliberada e analisada a (in) constitucionalidade. Tal sistema de controle de constitucionalidade, além de difuso, se caracteriza por ser incidental e concreto, havendo possibilidade de ser proposto por qualquer interessado perante a qualquer juiz ou tribunal, pressupondo conflito efetivo e não potencial, delimitado no caso concreto.

${ }^{25}$ COÊLHO, Bruna Fernandes. Sistemas De Controle De Constitucionalidade. In: Revista F@pciência, Apucarana-PR, v. 9, n. 13, 2012, p. 123 - 134.

${ }^{26}$ Id., ibid., p. 128.

${ }^{27}$ ALMEIDA, Vânia Hack. Controle de Constitucionalidade. Porto Alegre: Editora Verbo Jurídico, 2004. 


\section{SEPARAÇÃO DE PODERES: CONCEPÇÃo TEÓRICA E PRINCÍPIO CONSTITUCIONAL}

Segundo Sérgio Antônio Ferreira Victor ${ }^{28}$ a concepção da separação de poderes quando passa a ideia de que existem vários poderes é equivocada, uma vez que o poder estatal é unitário (uno, indivisível), devendo estar relacionada sim à ideia de existência de uma divisão funcional do poder entre os órgãos que devem se equilibrar por meio de um conjunto de razões constitucionais. A ideia da separação dos poderes, assim, está vinculada à tentativa de não se permitir o enfeixamento ou a concentração do poder nas mãos de uma só pessoa ou de um grupo restrito, estabelecendo o controle necessário para que sejam asseguradas as liberdades individuais e a própria democracia. De acordo com Lênio Luiz Streck $^{29}$ a tradição jurídica que fundamenta o constitucionalismo institucionaliza a separação dos poderes, visando que um controle o outro (checks and balances), sendo o Judiciário o poder com salvaguarda para eventuais rupturas.

Especificamente em âmbito nacional, a separação dos poderes tem previsão no artigo $2^{\circ}$ do Diploma Constitucional vigente, com o constituinte determinando que os poderes da União (Legislativo, Executivo e Judiciário) são harmônicos entre si, devido ao seu grau de importância e em seu entendimento como clausula pétrea, estando a separação de poderes inserida num contexto jurídico de imutabilidade perante o Estado Democrático de Direito.

De acordo com Jorge Carlos Silva Lustosa ${ }^{30}$ o princípio da Separação dos Poderes relaciona-se aos fundamentos do Estado Democrático de Direito, sendo viabilizado a partir da concepção de Aristóteles quanto à 'tripartição dos poderes', baseada em três funções distintas: editar normas gerais que são de observância obrigatória por todos (1); de colocar em prática normas editadas numa situação fática (2); e a função de julgar, sanando conflitos de interesses da aplicação das normas aos casos concretos (3).

Nesse sentido:

\footnotetext{
${ }^{28}$ VICTOR, Sérgio Antônio Ferreira (org). Separação de Poderes. IDP, 1. edição, Brasília, 2015.

${ }^{29}$ STRECK, Lenio Luiz. Jurisdição constitucional e decisão jurídica. São Paulo: Editora Revista dos Tribunais, 2013.

${ }^{30}$ LUSTOSA, Jorge Carlos Silva. A Legitimidade do poder normativo das agências reguladoras: Análise a partir do princípio constitucional da separação de poderes. IDP, Brasília, 2012.
} 
Revista Eletrônica de Direito Processual - REDP.

Rio de Janeiro. Ano 13. Volume 20. Número 2. Maio a Agosto de 2019

Periódico Quadrimestral da Pós-Graduação Stricto Sensu em Direito Processual da UERJ

Patrono: José Carlos Barbosa Moreira (in mem.). ISSN 1982-7636. pp. 74-95

www.redp.uerj.br

\begin{abstract}
A Constituição da República Federativa do Brasil de 1988, corolário da
Declaração Francesa, traz em seu texto a tripartição de poderes: o Legislativo, o

Executivo e o Judiciário. Porém, vai além, prevê proteção a esse princípio quando o eleva a nível de cláusula pétrea fundamental. Dessa forma, o princípio fundamental da separação dos poderes está descrito expressamente no artigo 60, $\S 4^{\circ}$, inciso III: "Não será objeto de deliberação a proposta de emenda tendente a abolir: (...) III- a separação dos poderes". ${ }^{31}$
\end{abstract}

A separação de poderes, de tal forma, consiste em um único poder, o qual é 'repartido' dentre as atribuições dos três poderes estatais: O Poder Executivo, o Poder Legislativo e o Poder Judiciário.

De acordo com Rodrigo Pires da Cunha Boldrini ${ }^{32}$ a separação dos poderes possibilita o funcionamento perpétuo do Estado Democrático de Direito, com os poderes estatais independentes e harmônicos entre si, repartindo entre eles as funções estatais e prevendo prerrogativas e imunidades para o exercício de cada poder. Essa repartição, segundo o autor, promove a manutenção do poder estatal, evitando que sejam coibidos abusos através da independência entre os três poderes, pois, do contrário, haveria o aparelhamento do Estado, no qual os três poderes existem em uma representação única.

Cid Marconi Gurgel de Souza ${ }^{33}$ aponta que a separação de poderes deve estar prevista em toda e qualquer constituição democrática (condição sine qua non de qualquer Constituição). Ora, assim como os preceitos da razoabilidade e da proporcionalidade, bem como o controle difuso de constitucionalidade asseguram o devido funcionamento do Estado Democrático de Direito, com base nos preceitos jurídicos estabelecidos ao longo da concepção histórica do Estado.

\title{
6 PROPORCIONALIDADE E RAZOABILIDADE NO CONTROLE DIFUSO DE CONSTITUCIONALIDADE E NA SEPARAÇÃO DE PODERES
}

\footnotetext{
${ }^{31}$ Id., Ibid., p. 15.

32 BOLDRINI, Rodrigo Pires da Cunha. Garantia de direitos e separação dos Poderes. Dissertação de Mestrado. São Paulo: FADUSP, 2012.

33 SOUZA, Cid Marconi Gurgel de. Separação e conflito de poderes - descumprimento de ordens judiciais. Dissertação (mestrado) - Universidade de Fortaleza, 2008.
} 
Revista Eletrônica de Direito Processual - REDP.

Rio de Janeiro. Ano 13. Volume 20. Número 2. Maio a Agosto de 2019

Periódico Quadrimestral da Pós-Graduação Stricto Sensu em Direito Processual da UERJ

Patrono: José Carlos Barbosa Moreira (in mem.). ISSN 1982-7636. pp. 74-95

www.redp.uerj.br

De acordo com Gerson Luiz Rocha ${ }^{34}$ o controle de constitucionalidade a partir da normatividade dos princípios exige uma metodologia apropriada. Para o autor, o princípio da proporcionalidade tem servido como fundamento para as decisões que entram na esfera discricionária do legislador ordinário, para que sejam visíveis os fundamentos mínimos necessários ao preenchimento dos requisitos teóricos de acordo com sua aplicabilidade.

Paulo Bonavides ${ }^{35}$, por sua vez, aponta que os princípios da proporcionalidade e razoabilidade devem ser aplicados de modo racional, sustentando os valores constitucionais. Tais princípios são aplicados pelos tribunais dentro de um contexto de interpretação tópica, sem o acompanhamento de uma argumentação densa para demonstrar a validade da conclusão. Para o autor, o que ocorre nos tribunais brasileiros no âmbito do controle difuso de constitucionalidade diz respeito à simples menção da proporcionalidade/razoabilidade, sem grande aprofundamento, para que se adote uma solução abstrata em detrimento de outra, concluindo que a solução adotada seria mais justa, seguindo o senso comum de acordo com o tema sob o qual se decide.

Dentro desse contexto, é indispensável verificar como a Suprema Corte aborda tais princípios:

\begin{abstract}
Ao se buscar o entendimento do Supremo Tribunal Federal acerca da aplicação do princípio da proporcionalidade, a primeira observação que se mostra pertinente é a de que a Corte, absolutamente, não trata o tema de modo racionalmente estruturado. Na maioria das vezes não é feita qualquer distinção entre razoabilidade e proporcionalidade, valendo-se dos termos como se sinônimos fossem, além de utilizarem-se os institutos de modo puramente retórico, sem uma maior preocupação com a análise pormenorizada dos elementos que compõem o teste de proporcionalidade. ${ }^{36}$
\end{abstract}

Virgílio Afonso Silva ${ }^{37}$, ao analisar as decisões do STF nesse sentido contempla que a invocação da proporcionalidade acaba detendo caráter meramente retórico e não sistemático, sendo tal prerrogativa observada em inúmeras decisões. A utilização da fórmula à luz do princípio da proporcionalidade ou da razoabilidade', de tal forma, acaba

\footnotetext{
${ }^{34}$ ROCHA, Gerson Luiz. O Princípio Da Proporcionalidade E O Controle De Constitucionalidade Da Lei: A Problemática Do Decisionismo Judicial. 2017. Disponível em: <https://revista.jfpe.jus.br/index.php/RJSJPE/article/download/149/140> Acesso: Nov. 2017.

${ }^{35}$ BONAVIDES, Paulo. Curso de direito constitucional. São Paulo: Malheiros, 2003.

${ }^{36}$ ROCHA, Gerson Luiz. Op. Cit., p. 121.

${ }^{37}$ SILVA, Virgílio Afonso da. Op. Cit.
} 
Revista Eletrônica de Direito Processual - REDP.

Rio de Janeiro. Ano 13. Volume 20. Número 2. Maio a Agosto de 2019

Periódico Quadrimestral da Pós-Graduação Stricto Sensu em Direito Processual da UERJ

Patrono: José Carlos Barbosa Moreira (in mem.). ISSN 1982-7636. pp. 74-95

www.redp.uerj.br

por considerar atos inconstitucionais. Trata-se da justificação de um ponto de vista interno, sendo inconsistente no âmbito da justificação externa, demonstrando a compatibilidade destes meios e fins com ações permitidas pelo ordenamento constitucional.

Gerson Luiz Rocha ${ }^{38}$, no mesmo sentido, observou que no âmbito do controle de constitucionalidade, é comum que se faça uso da proporcionalidade e da razoabilidade como sinônimos, fato que torna sua utilização enquanto fórmula banalizada, uma vez que, conforme observado, a proporcionalidade e razoabilidade, ainda que detenham objetivos alinhados, não se confundem. Para o autor, a adequada utilização de tais princípios de interpretação advém inicialmente da distinção entre a proporcionalidade e a razoabilidade, o que não ocorre ao analisar a jurisprudência brasileira, que banaliza ambos os termos e faz uso de tais fundamentos de modo abstrato, incoerente e banalizado.

Henrique Garbellini Carnio ${ }^{39}$ também destaca tal assertiva, identificando que historicamente as concepções de proporcionalidade/razoabilidade têm sido demasiadamente recorridas, abordando-se como um dos temas que mais está em voga nas discussões atuais sobre o direito.

Para o autor o que vem ocorrendo "é uma banalização na utilização do princípio da proporcionalidade. Ocorre uma verdadeira trivialização de sua importância sobre o assunto com expressões vazias que apenas evocam a figura do bacharel capaz de dizer belas coisas". ${ }^{40}$

De tal modo, os tribunais e julgadores fazem uso da razoabilidade e da proporcionalidade de modo abstrato, sem ater-se aos conceitos e fundamentos para a aplicabilidade dos métodos embasados por tais concepções. Tal realidade, entretanto, não é observada tão somente no controle difuso de constitucionalidade, mas também em outras modalidades do controle de constitucionalidade. Sob essa perspectiva, tais fundamentos são aplicados em âmbito nacional, enfraquecendo ainda o cumprimento a determinados princípios constitucionais, como ocorre com o princípio da separação de poderes.

\footnotetext{
${ }^{38}$ ROCHA, Gerson Luiz. Op. Cit., p. 121.

${ }^{39}$ CARNIO, Henrique Garbellini. Princípios da Proporcionalidade e da Razoabilidade: Apontamentos a partir da Teoria Alemã da Proporcionalidade. In: Revista Jurídica Uniaraxá, Araxá, v. 15, n. 14, p. 101-112, 2011.

${ }^{40}$ Id., ibid., p. 102.
} 
Revista Eletrônica de Direito Processual - REDP.

Rio de Janeiro. Ano 13. Volume 20. Número 2. Maio a Agosto de 2019

Periódico Quadrimestral da Pós-Graduação Stricto Sensu em Direito Processual da UERJ

Patrono: José Carlos Barbosa Moreira (in mem.). ISSN 1982-7636. pp. 74-95

www.redp.uerj.br

Victor Augusto Vieira ${ }^{41}$ aprofundou tal questão em seu estudo verificando que os critérios da razoabilidade e proporcionalidade são fundamentados para impedir decisões judiciais exageradas, que desrespeitam a separação dos poderes. Para o autor, os direitos fundamentais vinculam o Legislativo e o Executivo, exigindo o respeito no exercício da atividade de tais poderes. O Judiciário, por sua vez, se encontra vinculado tanto às leis como às demais normas que vigoram no ordenamento jurídico, de modo que o critério da proporcionalidade/razoabilidade vincula o Poder Judiciário e veda decisões excessivas, que preconizem o desrespeito à separação dos poderes enquanto fundamento do Estado Democrático de Direito.

Dimitri Dimoulis e Leonardo Martins ${ }^{42}$ apontam que o critério da proporcionalidade, quando devidamente entendido e aplicado, veta a politização do direito e contribui para a concretização do princípio constitucional da separação de poderes previsto no artigo $2^{\circ}$ da $\mathrm{CRFB} / 88$. Entretanto, para os autores, a banalização da razoabilidade/proporcionalidade propicia um contexto no qual é possibilizada a politização do judiciário, atacando diretamente ao princípio em questão.

Assim:

(...) o Poder Judiciário deve-se pautar em critérios objetivos no momento de decidir um caso de judicialização dos direitos fundamentais. Esses critérios decorrem da proporcionalidade, que evita o exagero das decisões judiciais interventoras nas políticas públicas de saúde, bem como limita a atuação dos magistrados. Por meio da proporcionalidade, busca-se uma aproximação entre o Poder Judiciário e o Poder Executivo para favorecer aqueles que se sentem afetados. Para lograr êxito nessa aproximação e preservar a separação dos poderes, o Judiciário deve obrigatoriamente e fundamentar suas decisões utilizando-se o critério da proporcionalidade. ${ }^{43}$

De acordo com Tassarini (2012), ao analisar a questão da judicialização, a própria noção do constitucionalismo em suas mais variadas acepções (seja como conjunto dos mecanismos normativos e institucionais de um sistema jurídico-político que organizam os poderes do Estrado e protegem os direitos fundamentais dos cidadãos), a autora a distingue

41 VIEIRA, Victor Augusto. A Proporcionalidade Como Critério Limitador Da Intervenção Do Poder Judiciário Nas Políticas Públicas De Saúde. In: SynThesis Revista Digital FAPAM, Pará de Minas, v.6, n.6, 355-370, dez. 2015.

${ }^{42}$ DIMOULIS, Dimitri; MARTINS, Leonardo. Teoria geral dos direitos fundamentais. 5. ed. rev. atual. e ampl. São Paulo: Atlas, 2014.

${ }^{43}$ VIEIRA, Victor Augusto. Op. cit., p. 363. 
Revista Eletrônica de Direito Processual - REDP.

Rio de Janeiro. Ano 13. Volume 20. Número 2. Maio a Agosto de 2019

Periódico Quadrimestral da Pós-Graduação Stricto Sensu em Direito Processual da UERJ

Patrono: José Carlos Barbosa Moreira (in mem.). ISSN 1982-7636. pp. 74-95

www.redp.uerj.br

do ativismo judicial, que é a concepção através da qual o Poder judiciário busca ter uma maior participação na concretização dos fins constitucionais, inclusive interferindo em outros poderes.

Nesse sentido:

(...) o ativismo judicial revela-se como um problema exclusivamente jurídico (ou seja, criado pelo Direito, mas, evidentemente, com consequências em todas as demais esferas), sobre o qual a comunidade jurídica deve, primeiro, debruçar-se no interesse de perguntar por seu sentido, para posteriormente apresentar uma resposta, na senda de um constitucionalismo democrático. E, no questionamento de como pode ser compreendida a manifestação judiciária, é possível encontrar posicionamentos que retrataram a indexação da decisão judicial a um ato de vontade daquele que julga. ${ }^{44}$

Dada tal elucidação, contempla-se que:

O critério da proporcionalidade impede a politização do judiciário e quando corretamente entendido e aplicado concretiza o princípio constitucional da separação dos poderes. Atualmente, a Lei $\mathrm{n}^{\mathrm{o}}$ 13.105, de 16 de março de 2015 consagrou o critério da proporcionalidade como norteador do novo Código de Processo Civil brasileiro, não deixando dúvidas sobre a vinculação do Poder Judiciário ao referido critério. Assim sendo, as decisões judiciais interventoras em políticas públicas devem se pautar na proporcionalidade, sob pena de invalidade das mesmas. ${ }^{45}$

Ora, a banalização dos critérios de proporcionalidade e razoabilidade propicia que tais fundamentos não sejam aplicados verdadeiramente no âmbito tanto do controle difuso de constitucionalidade quanto no âmbito da obediência ao princípio da separação de poderes, culminando em um contexto jurídico no qual não ocorre o devido respeito aos princípios e garantias previstos pelo constituinte.

Para Henrique Garbellini Carnio ${ }^{46}$ o entendimento dos princípios/critérios da proporcionalidade e razoabilidade como fórmulas amplamente aplicadas no contexto

\footnotetext{
${ }^{44}$ OLIVEIRA, Rafael Tomaz de; TASSARINI, Clarissa. Ativismo Judicial e Judicialização da Política: notas para uma necessária diferenciação. In: Antônio Pereira Gaio Júnior; Marcio Gil Tostes dos Santos (Org.). Constituição Brasileira de 1988: Reflexões em Comemoração ao seu $25^{\circ}$ Aniversário. Curitiba: Juruá, 2014, p. 92.

${ }^{45}$ VIEIRA, Victor Augusto. Op. Cit., p. 367.

${ }^{46}$ CARNIO, Henrique Garbellini. Op. Cit.
} 
Revista Eletrônica de Direito Processual - REDP.

Rio de Janeiro. Ano 13. Volume 20. Número 2. Maio a Agosto de 2019

Periódico Quadrimestral da Pós-Graduação Stricto Sensu em Direito Processual da UERJ

Patrono: José Carlos Barbosa Moreira (in mem.). ISSN 1982-7636. pp. 74-95

www.redp.uerj.br

jurídico brasileiro da atualidade promovem a banalização dos mesmos, sendo tal banalização uma atitude habitual que virou comum na seara jurídica.

O autor supramencionado ainda aponta que o uso correto do princípio da razoabilidade advém de uma utilização mais específica e procedimental, de modo que em âmbito nacional é o princípio da razoabilidade que vem sendo utilizado de modo absurdamente discricionário e não o princípio da proporcionalidade. $\mathrm{O}$ uso desmesurado dos dois princípios de maneira banalizada, assim impede que sejam atendidos os critérios que justificam a existência de ambos os princípios.

Assim, a realidade jurídica brasileira evidenciada na atualidade proporciona um descaso generalizado quanto ao uso adequado dos princípios da razoabilidade e da proporcionalidade, contemplando ambos como sinônimos e, de tal forma, contribuindo para que seja desrespeitado o princípio da separação de poderes e, no mesmo sentido, para que ocorram consequências a curto e longo prazo no âmbito do controle difuso de constitucionalidade.

\section{CONSIDERAÇÕES FINAIS}

As discussões envolvendo as concepções de proporcionalidade e razoabilidade dentro do contexto jurídico contemporâneo vem ocupando um grande espaço nas teorias levantadas pela doutrina e pela jurisprudência como um todo. Tais teorias são emergentes em âmbito nacional, sobretudo diante da banalização de tais princípios/regras, que são utilizados como uma espécie de 'fórmula mágica' para que seja deliberada uma determinada matéria, possibilitando decisões arbitrárias com base no uso inadequados de tais elementos jurídicos de vital importância para a manutenção do Estado Democrático de Direito.

O presente estudo buscou analisar a banalização dos princípios da razoabilidade e da proporcionalidade em âmbito nacional, sobretudo verificando as consequências de tal banalização no âmbito do controle difuso de constitucionalidade e na obediência do princípio de separação dos poderes.

Conforme apontado, as concepções de razoabilidade e de proporcionalidade vem sendo utilizadas de modo recorrente e demasiado, o que por si só já diz respeito à banalização da utilização de tais princípios e regras correlacionadas. Entretanto, ocorre, 
sobretudo no âmbito do controle difuso de constitucionalidade o tratamento da razoabilidade e da proporcionalidade como sinônimos, o que, conforme apresentado no presente estudo, inviabiliza a plena compreensão e aplicação destes. Essa trivialização, de tal modo, desponta consequências jurídicas que incubem ao não alcance dos objetivos reais de tais princípios, com o intuito de consolidar o funcionamento e manutenção do Estado Democrático de Direito.

No mesmo sentido, a banalização de tais princípios também desrespeita a separação dos poderes, sobretudo no âmbito do Judiciário, não vedando decisões excessivas e arbitrárias que desrespeitam as prerrogativas fundamentais da separação dos poderes, princípio constitucional que também, assim como o controle difuso de constitucionalidade e a aplicação dos princípios da razoabilidade e da proporcionalidade, buscam assegurar a manutenção e o funcionamento do Estado e da própria Constituição.

\section{REFERÊNCIAS}

ALMEIDA, Vânia Hack. Controle de Constitucionalidade. Porto Alegre: Editora Verbo Jurídico, 2004.

BARROSO, Luís Roberto. Controle de Constitucionalidade no Direito Brasileiro. 2. ed. Rio de Janeiro: Saraiva, 2006.

BOLDRINI, Rodrigues Pires da Cunha. Garantia de direitos e separação dos Poderes. Dissertação de Mestrado. São Paulo: FADUSP, 2012.

BONAVIDES, Paulo. Curso de direito constitucional. São Paulo: Malheiros, 2003.

CARNIO, Henrique Garbellini. Princípios da Proporcionalidade e da Razoabilidade: Apontamentos a partir da Teoria Alemã da Proporcionalidade. In: Revista Jurídica Uniaraxá, Araxá, v. 15, n. 14, p. 101-112, 2011.

CEZNE, Andreia Nárriman. A teoria dos direitos fundamentais: uma análise comparativa das perspectivas de Ronald Dworkin e Robert Alexy. In: Revista de Direito Constitucional e Internacional, v.13, n. 52, pp. 51- 67, São Paulo: 2005.

COÊLHO, Bruna Fernandes. Sistemas de controle de constitucionalidade. In: Revista F@pciência, Apucarana-PR, ISSN 1984-2333, v.9, n. 13, p. 123 - 134, 2012.

DANTAS, Ivo. Princípios constitucionais e interpretação constitucional. Rio de Janeiro: Lumen Juris, 1995.

DIMOULIS, Dimitri; MARTINS, Leonardo. Teoria geral dos direitos fundamentais. 5. ed. rev. atual. e ampl. São Paulo: Atlas, 2014. 
DOBRIANSKYJ, Virgínia de Oliveira Rosa. O princípio da proporcionalidade como critério de aplicação da pena. Dissertação apresentada à Pontifícia Universidade Católica (PUC) de São Paulo. São Paulo, 2009.

DWORKIN, Ronald. Uma questão de princípio. Trad. Luis Carlos Borges. 2. ed. São Paulo: Martins Fontes, 2005.

LUSTOSA, Jorge Carlos Silva. A Legitimidade do poder normativo das agências reguladoras: Análise a partir do princípio constitucional da separação de poderes. IDP, Brasília, 2012.

MASTRODI, Josué. Ponderação de direitos e proporcionalidade das decisões judiciais. In: Revista Direito FGV, São Paulo 10(2) | P. 577-596 | Jul-Dez 2014.

MELLO, Celso Antônio Bandeira de apud Carlos Ari Sundeld. Fundamentos de direito público. 3. ed. São Paulo: Ed. Malheiros, 2009.

OLIVEIRA, Fábio. Por uma teoria dos princípios: o princípio constitucional da razoabilidade. 2 ed. Rio de Janeiro: Lúmen Juris, 2007.

OLIVEIRA, Rafael Tomaz de; TASSARINI, Clarissa. Ativismo Judicial e Judicialização da Política: notas para uma necessária diferenciação. In: Antônio Pereira Gaio Júnior; Marcio Gil Tostes dos Santos (Org.). Constituição Brasileira de 1988: Reflexões em Comemoração ao seu $25^{\circ}$ Aniversário. Curitiba: Juruá, 2014, p. 71-92 PAIVA, Eduardo de Azevedo. Princípios Gerais de Direito e Princípios Constitucionais. Série Aperfeiçoamento de Magistrados 11 - Curso de Constitucional - Normatividade Jurídica, 2012.

PEIXOTO, Alexandre Sivolella et al. O princípio da razoabilidade. In: Revista Jurídica UNIGRAN. Dourados, MS, v. 6, n. 11, Jan./Jul. 2004.

PESSOA, Laura Scalldaferri. Os Princípios Gerais do Direito na Integração das Normas. In: Revista REDE, n. 20, Salvador, out-dez/2009.

PONTES, Helenilson Cunha. O princípio da proporcionalidade e o direito tributário. São Paulo: Ed. Dialética, 2000.

ROBERTO, Karina; SILVA, Nelson Finotti. A regra da proporcionalidade e o princípio da razoabilidade. In: Revista Eletrônica Direito e Política, Programa de PósGraduação Stricto Sensu em Ciência Jurídica da UNIVALI, Itajaí, v.7, n.2, $2^{\circ}$ quadrimestre de 2012 
ROCHA, Gerson Luiz. O Princípio Da Proporcionalidade E O Controle De

Constitucionalidade Da Lei: A Problemática Do Decisionismo Judicial. 2017.

Disponível

em:

$<$ https://revista.jfpe.jus.br/index.php/RJSJPE/article/download/149/140> Acesso: Nov/2017.

SILVA, Ana Paula Caldin da. Aplicação dos princípios da razoabilidade e da proporcionalidade na jurisprudência tributária brasileira. Dissertação (Mestrado em Direito Político e Econômico) - Universidade Presbiteriana Mackenzie, São Paulo, 2010.

SILVA, José Afonso da. Os princípios constitucionais fundamentais. Rev. Trib. Reg. Fed., 1ª edição, Brasília, out/dez, 1994, p. 17-22.

SILVA, Virgílio Afonso da. O proporcional e o razoável. Revista dos Tribunais 798 (2002): 23-50.

SILVA, Virgílio Afonso da. Princípios e regras: mitos e equívocos acerca de uma distinção. In: Revista Latino-Americana de Estudos Constitucionais nº. 1, 2003: 607-630.

SOUZA, Cid Marconi Gurgel de. Separação e conflito de poderes - descumprimento de ordens judiciais. Dissertação (mestrado) - Universidade de Fortaleza, 2008.

STRECK, Lenio Luiz. As Recepções Teóricas Inadequadas Em Terrae Brasilis. In: Revista de Direitos Fundamentais e Democracia, Curitiba, v. 10, n. 10, p. 2-37, jul./dez. 2011.

STRECK, Lenio Luiz. Jurisdição constitucional e decisão jurídica. São Paulo: Editora Revista dos Tribunais, 2013.

VICTOR, Sérgio Antônio Ferreira (org). Separação de Poderes. IDP, 1. edição, Brasília, 2015.

VIEIRA, Victor Augusto. A Proporcionalidade Como Critério Limitador Da Intervenção Do Poder Judiciário Nas Políticas Públicas De Saúde. In: SynThesis Revista Digital FAPAM, Pará de Minas, v.6, n.6, 355-370, dez. 2015.

VILHENA, Leonardo Carneiro. Os Princípios Constitucionais Da Razoabilidade E Da Proporcionalidade E O Direito Tributário. Monografia apresentada ao PósGraduação Lato Sensu do Instituto Brasiliense de Direito Público - IDP, Brasília, 2011. 